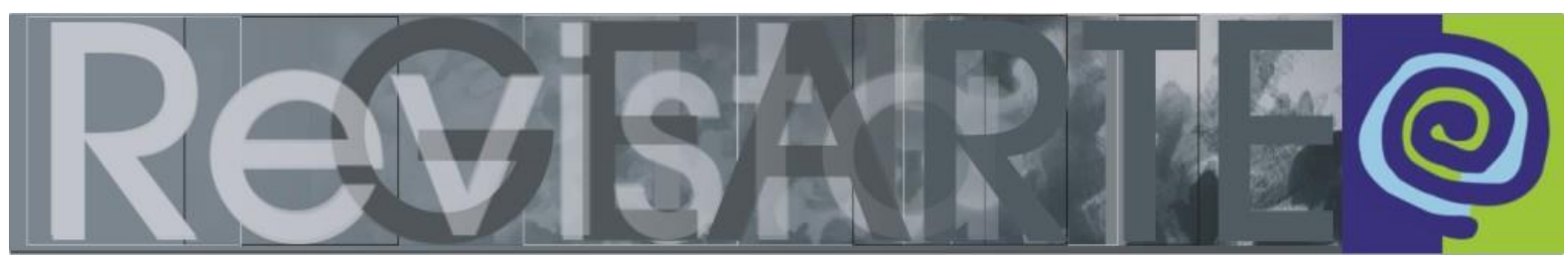

e-ISSN 2357-9854

\title{
Outros objetos, outras leituras: estudo das relações entre as linguagens em zines e publicações alternativas com base na semiótica discursiva
}

\author{
Ruth Rejane Perleberg Lerm (Instituto Federal de Educação, \\ Ciência e Tecnologia Sul-rio-grandense — IFSul, Pelotas/RS, Brasil)
}

\begin{abstract}
RESUMO - Outros objetos, outras leituras: estudo das relações entre as linguagens em zines e publicações alternativas com base na semiótica discursiva - No presente artigo apresentamos parte da Tese de Doutorado em Educação intitulada Leitura de textos sincréticos verbovisuais: relações entre linguagens em (fan)zines brasileiros, concluída no Programa de Pós-Gradução em Educação da Universidade Federal do Rio Grande do Sul (UFRGS) em 2017. A pesquisa teve como objetivo estudar as relações entre as linguagens em zines, publicações alternativas de mídia impressa e contou com o aporte teórico e metodológico da Semiótica Discursiva. Dentre os autores consultados, citamos as contribuições de Barros (2003), Fiorin (2004; 2009), Teixeira (2004; 2009), Greimas e Courtés (1991; 2008), Hjelmslev (1978; 2006) e Carmo Jr. (2009). A partir das análises de Acordo mal e Em branco de Hannah Uesugi e Pequeno compêndio dos fantasmas interiores, de Ale Kalko constatamos entre seus componentes relações de interdependência que, por sua vez, foram examinadas quanto a três dimensões: direção, intimidade e objetividade.
\end{abstract}

PALAVRAS-CHAVE

Ensino da Arte. Semiótica Discursiva. Sincretismo. Fanzine. Zine.

RESUMEN - Otros objetos, otras lecturas: estudio de las relaciones entre los lenguajes en zines y publicaciones alternativas con base en la semiótica discursiva - En el presente artículo presentamos parte de la Tesis de Doctorado en Educación titulada Lectura de textos sincréticos verbo visuales: relaciones entre lenguajes en (fan)zines brasileños, concluida en el Programa de Postgrado en Educación de la Universidade Federal do Rio Grande do Sul (UFRGS) en 2017. La investigación tuvo como objetivo estudiar las relaciones entre los lenguajes en zines, publicaciones alternativas de medios impresos y contó con el aporte teórico y metodológico de la Semiótica Discursiva. De los autores consultados, citamos las contribuciones de Barros (2003), Fiorin (2004; 2009), Teixeira (2004; 2009), Greimas y Courtés (1991; 2008), Hjelmslev (1978; 2006) y Carmo Jr. (2009). A partir de los análisis de Acordo mal y Em branco de Hannah Uesugi y Pequeno compêndio dos fantasmas interiores, de Ale Kalko constatamos entre sus componentes relaciones de interdependencia que, a su vez, fueron examinadas en cuanto a tres dimensiones: dirección, intimidad y objetividad.

PALABRAS CLAVE

Educación Artística. Semiótica Discursiva. Sincretismo. Fanzine. Zine.

Neste artigo apresentamos parte da Tese de Doutorado em Educação intitulada Leitura de textos sincréticos verbovisuais: relações entre linguagens em (fan)zines brasileiros, concluída no Programa de Pós-Gradução em Educação da Universidade Federal do Rio Grande do Sul (UFRGS) em 2017, sob orientação da Profa. Dra. Analice Dutra Pillar. 
Na tese buscamos responder a dois problemas vivenciados pelo ensino da arte desde meados dos anos oitenta do século XX. O primeiro deles diz respeito à que visualidades lemos. Afetados pelos estudos do multiculturalismo e da cultura visual, observamos a gradual expansão do conceito de Arte e, com isso, o que entendemos por imagem, incluindo para a leitura em sala de aula as mais diversas manifestações culturais, dentre elas, textos sincréticos verbovisuais. Estes, por sua vez, trouxeram outras demandas: como ler estas manifestações que se apresentam em constante transformação? Quais aportes teóricos poderiam dar conta destes textos?

Pensando nessas questões, realizamos um recorte na produção contemporânea de publicações alternativas, optando pela leitura dos fanzines ou simplesmente zines. Em seus primórdios, o termo fanzine surgiu para designar produções de baixo custo, de pequena circulação, na maioria das vezes publicados, produzidos e distribuídos por admiradores de ficção científica, ficção de fantasia e história em quadrinhos (HQ). Ao longo dos anos se converteram em um dos grandes produtos da contracultura e do movimento underground e atualmente têm assumido os mais variados propósitos e novas designações, como perzines e parental zines. Para abarcar o maior número de produções que não se enquadram na tradicional "revista de fã", observamos o uso cada vez mais frequente do termo zine.

A escolha deste objeto empírico de estudo surgiu da observação/constatação de vários fatos e fenômenos. O primeiro deles diz respeito a nossa experiência em sala de aula, onde alunos da área de Design demonstraram grande interesse pela leitura e criação de zines. Semelhante empenho de alunos e professores encontramos em publicações brasileiras recentes que trazem relatos de experiências significativas com fanzines no ensino fundamental, médio e superior (PINTO, 2013) e fora do contexto escolar (MUNIZ, 2010).

Outro fenômeno que observamos foi o aumento de publicações específicas nas áreas de Comunicação e Design (LUPTON, 2011) sobre mídia impressa independente, nas quais o fanzine é valorizado como objeto de grandes possibilidades gráficas. Consideramos que tal interesse se deve, em boa parte, ao próprio meio fanzine: como produções alternativas, independentes, estão à margem do grande 
mercado editorial, portanto, livres de suas imposições, configurando-se num espaço aberto para novas experiências expressivas e conceituais.

Constatamos, também, o surgimento dos zine fests ou festivais de zines, eventos voltados para a cultura zine e DIY que envolvem a exposição, troca e venda de zines e publicações alternativas. A partir da descrição e do acompanhamento de cinco eventos realizados nos Estados Unidos - Atlanta Zine Fest (AZF), Brooklyn Zine Fest (BZF), Chicago Zine Fest (CZF), Los Angeles Zine Fest (LA Zine Fest), San Francisco Zine Fest (SFZF) e Scranton Zine Fest - e um no Brasil (Ugra Zine Fest) comprovamos tratar-se de um movimento em expansão. Relativamente novos (o mais antigo destes data de 2001) os zine fests têm apresentado um crescimento significativo de participantes e expositores a cada edição e as programações inicialmente concentradas em um dia têm sido expandidas para dois. Além de contemplarem a exposição, feira, palestras, painéis, debates e oficinas, costumam ser encerrados com apresentações musicais o que, aliado ao fato de serem gratuitos em sua maioria, acabam por se constituir em espaços de divulgação, encontro e lazer para fanzineiros, desenhistas, quadrinhistas e público em geral.

Por outro lado, na busca pelo que já se escreveu sobre fanzines no Brasil, observamos a escassez tanto de livros como de pesquisas acadêmicas. Dentre as poucas publicações encontradas, destacamos três autores que contribuíram para a investigação: Fredric Wertham (1973), Teal Triggs (2010) e Henrique Magalhães (1993, 2013). Do primeiro, em especial, colhemos um breve apanhado de conceitos e relatos sobre fanzines que oportunizaram uma visão geral de nosso objeto de estudo. As pesquisas acadêmicas sobre fanzines realizadas no Brasil também mostraram-se incipientes. Em levantamento realizado para a defesa do projeto de tese em 2014, em livros e bancos brasileiros de teses e dissertações, não encontramos pesquisas relacionadas ao termo zine e apenas cinco teses e dez dissertações para o termo fanzine. Dentre estas, somente em duas teses (ANDRAUS, 2006 e MUNIZ, 2009) e quatro dissertações (MAGALHÃES, 1990; PENTEADO, 2005; LOURENÇO, 2007 e NASCIMENTO, 2010) constatamos ser o fanzine o objeto de estudo das investigações. Nas demais, ele ocupa outras posições: corpus de análise ou parte da metodologia para obtenção de dados, meio expressivo para a construção da própria 
pesquisa ou objeto dela resultante. Também não localizamos pesquisas voltadas aos zines ou fanzines sob o ponto de vista teórico da semiótica discursiva.

Além dessas observações que apontaram para a necessidade de pesquisas sobre os zines, observamos que sua escolha como objeto empírico de estudo na tese foi ao encontro das necessidades e expectativas do ensino da arte contemporâneo. Como já citamos anteriormente, desde a década de 1980 várias são as metodologias, movimentos ou abordagens que não só defenderam politicamente a importância do ensino da arte em contextos formais de educação como inseriram a leitura da imagem como um de seus componentes fundamentais (BARBOSA, 1997). A imagem a ser lida, porém, vem sendo alterada nos últimos anos. As diversas vertentes pósmodernas como o multiculturalismo ou a nueva alfabetización reivindicaram que, além das imagens pertencentes ao cânone artístico estabelecido, imagens de primeira, fossem incluídos na leitura textos visuais e artefatos com significado especial para uma cultura e textos de mídia, imagens de segunda (JAGODZINSKI, 2005; ACASO, 2009). Pertencem a este segundo grupo os zines, textos presentes em nosso cotidiano que, assim como nossos tempos, situam-se na interterritorialidade, na marginalidade, nas bordas de diversas disciplinas ou áreas do conhecimento.

Ao escolhermos o zine como objeto empírico de estudo, procuramos, a exemplo de Barthes (1984, 1990, 2004), o inclassificável, não para classificá-lo, mas para dar uma voz a esta certa marginalidade. O autor, além de fornecer em sua obra recomendações indispensáveis para uma pesquisa como a fuga ao modismo e ao reducionismo, também nos auxiliou na escolha do corpus de análise. A par das justificativas até aqui apresentadas para a escolha do objeto que consideramos ser, usando as palavras de Barthes, da ordem do studium, do culturalmente construído, buscamos estar atentos ao punctum. Semelhante à fratura apresentada por Greimas (2002), o punctum ocorre quando textos ou práticas provocam certo estranhamento em quem as observa, quando algo simplesmente existe. No contato com um grande número de zines e publicações alternativas alguns simplesmente existiram para nós. Dentre eles, escolhemos três cuja visualidade e materialidade nos chamaram a atenção: Acordo mal e Em branco de Hannah Uesugi e Pequeno compêndio dos fantasmas interiores, de Ale Kalko. 
Como objetivo geral da pesquisa, buscamos estudar as relações entre as linguagens presentes nesses textos sincréticos verbovisuais e seus efeitos de sentido. Para tanto, contamos com o apoio teórico e metodológico da semiótica discursiva, disciplina construída a partir dos estudos de Algirdas Julien Greimas e que tem o sentido como objeto teórico de estudo. Alguns autores ligados a essa semiótica apresentaram conceitos fundamentais, como texto e sincretismo, e acabaram nos oferecendo suporte tanto teórico como metodológico, dentre eles, Barros (2003), Greimas e Courtés (1991, 2008), Teixeira $(2004,2009)$ e Fiorin (2009).

Para o estudo específico das relações entre linguagens no plano de expressão, retomamos os estudos de Carmo Jr. (2009) sobre os graus de intimidade entre linguagens adentrando em duas obras de Louis Hjelmslev: Prolegômenos a uma teoria da linguagem (2006) e La categoría de los casos (1978). Além de proporcionarem uma melhor compreensão da teoria de Hjelmslev, das nomenclaturas e definições por ele propostas, estas obras trouxeram subsídios que direcionaram a pesquisa como seus princípios de análise, a busca por uma descrição não contraditória, exaustiva e simples e o respeito a uma análise dedutiva, indo da classe ao componente, do componente ao componente e assim sucessivamente.

Talvez pudéssemos resumir a teoria de Hjelmslev em uma palavra: relação. Para o autor, bem como para a semiótica discursiva, o sentido não está nas coisas em si, mas nas relações entre suas partes: o caso expressa uma relação entre dois objetos; a relação entre dois objetos é sempre uma relação entre dois planos e também uma relação entre dimensões. Estas dimensões, por sua vez, pertencem a um sistema denominado por Hjelmslev em La categoría de los casos (1978) de sistema sublógico e são em número de três: (1) direção (aproximação-afastamento), (2) coerência-incoerência e (3) subjetividade-objetividade.

$\mathrm{Na}$ análise do corpus seguimos algumas etapas propostas por Teixeira (2004, 2009) para a análise de textos sincréticos verbovisuais e as adaptamos aos objetivos da pesquisa e às peculiaridades dos zines: (a) identificação das linguagens acionadas na construção do texto sincrético verbovisual; (b) descrição das categorias do plano de expressão verbovisual; (c) estudo das relações entre o plano da expressão e o 
plano do conteúdo; (d) descrição dos efeitos de sentido alcançados pela estratégia enunciativa adotada e (e) análise das relações entre as linguagens no plano de expressão verbovisual. Salientamos que durante as análises procuramos não perder de vista dois conceitos fundamentais para a compreensão dos textos sincréticos: a existência de uma enunciação sincrética e de apenas um plano do conteúdo e um plano de expressão. Com isso evitamos pensar em um plano de expressão e em uma enunciação para cada linguagem acionada na construção do texto verbovisual.

Nas três obras identificamos a presença das linguagens verbal escrita e visual e de seus elementos, grafemáticos e plásticos, respectivamente. Após a descrição das categorias eidéticas, cromáticas, matéricas e topológicas, passamos às possíveis relações entre estas categorias e aos efeitos de sentido provocados no plano de expressão e no plano do conteúdo. No plano do conteúdo não perfizemos o percurso gerativo, apenas buscamos as categorias semânticas do nível mais profundo, o fundamental.

Quanto às estratégias enunciativas adotadas, observamos semelhanças nas três obras. Em todas há a sobreposição de elementos e o jogo de velar/desvelar. Em Pequeno compêndio dos fantasmas interiores (Fig.1), imagens e palavras encontramse embaralhadas, desfocadas e somente através da sobreposição de papéis e consequente soma das cores tornam-se visíveis ou invisíveis. O jogo demonstra incerteza, insegurança: revela um sujeito hesitante ou incapaz de livrar-se de seus "fantasmas".

Figura 1: Pequeno Compêndio dos Fantasmas Interiores. Ale Kalko. P.1-2.
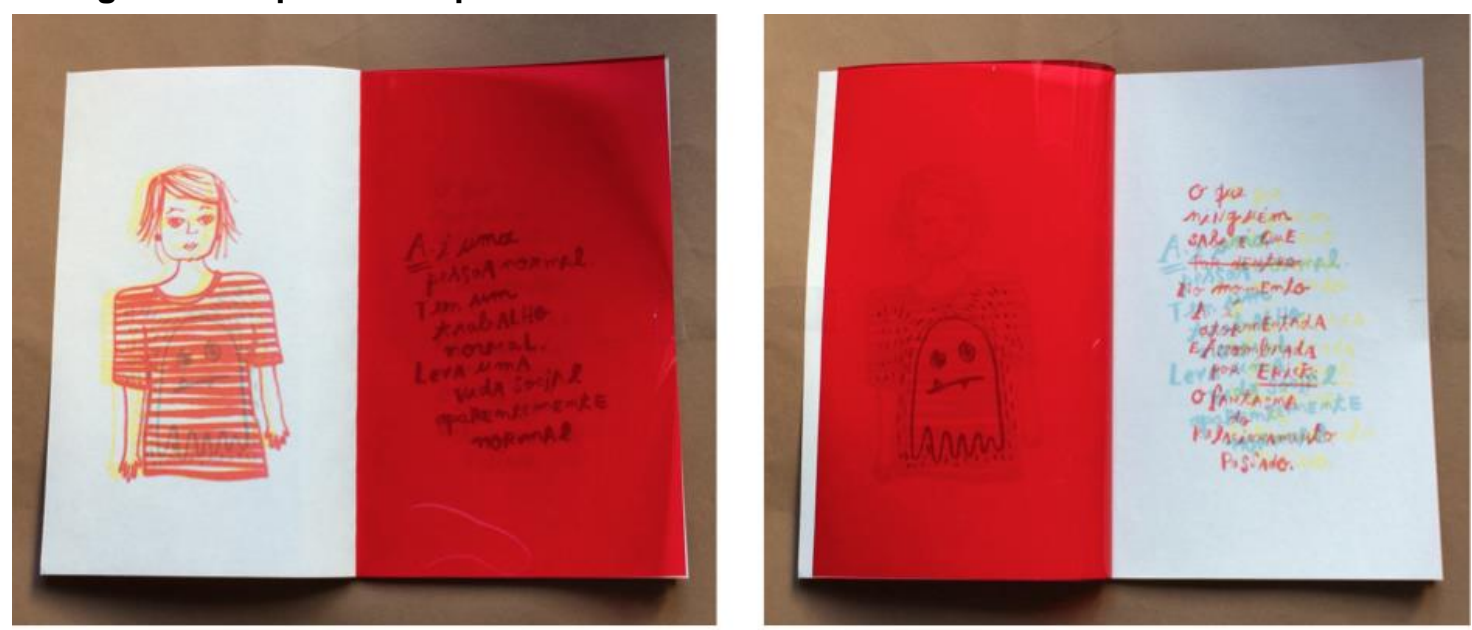

Fonte: Acervo da autora. 
Em Acordo mal (Fig.2) a sobreposição dos elementos grafemáticos e plásticos se dá a partir da sobreposição de folhas de papel. A materialidade da obra, a translucidez do papel, permite que vejamos várias camadas de linhas/tarjas e versos de um poema, sendo desvelados e velados, repetidamente e aos poucos. Aqui os efeitos também são de incerteza, de dúvida, de esquecimento.

Figura 2: Acordo mal. Hannah Uesugi, 2013. P.3-4.

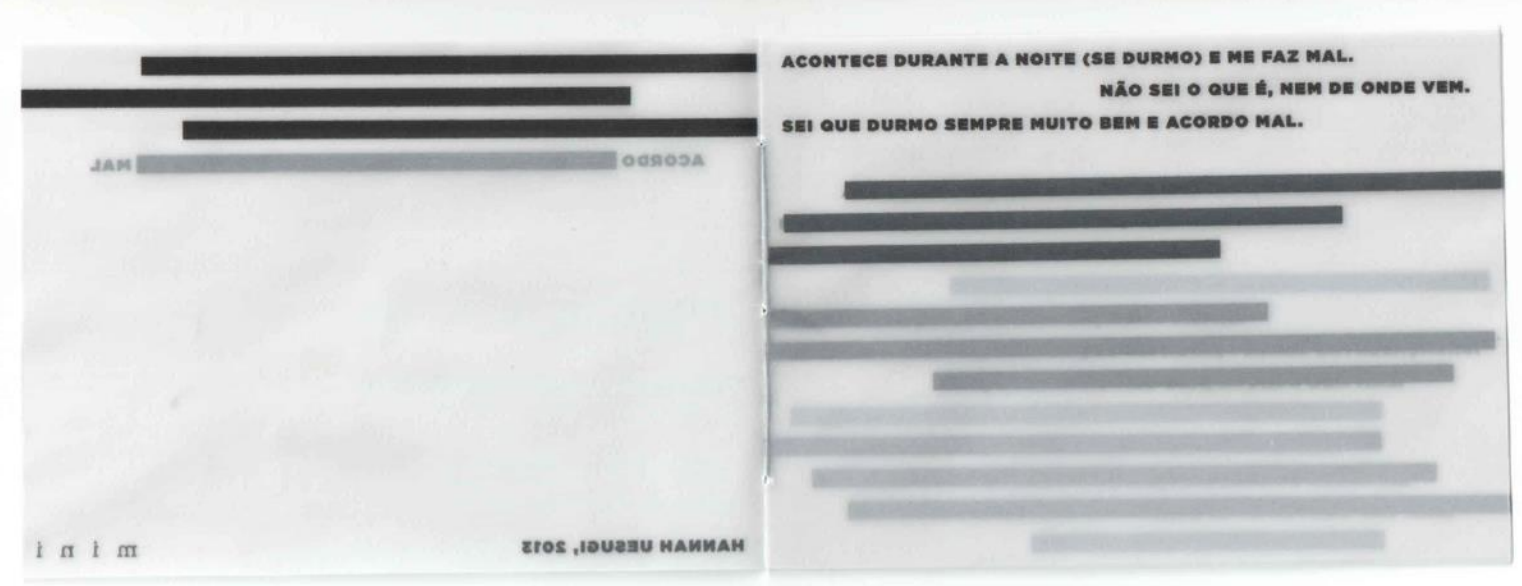

Fonte: Acervo da autora.

Na última obra, Em branco (Fig.3), manchas de tinta branca sobrepõem-se a palavras e sinais de pontuação de versos de um mesmo poema repetido várias vezes criando novas leituras a cada página. $O$ apagamento vai num crescendo até tornar-se total: após a repetição da expressão /em branco/ materializadas em manchas de corretor líquido, a autora sentencia "me deu branco". 
Figura 3 - Em branco. Hannah Uesugi, 2014. P.2-3.

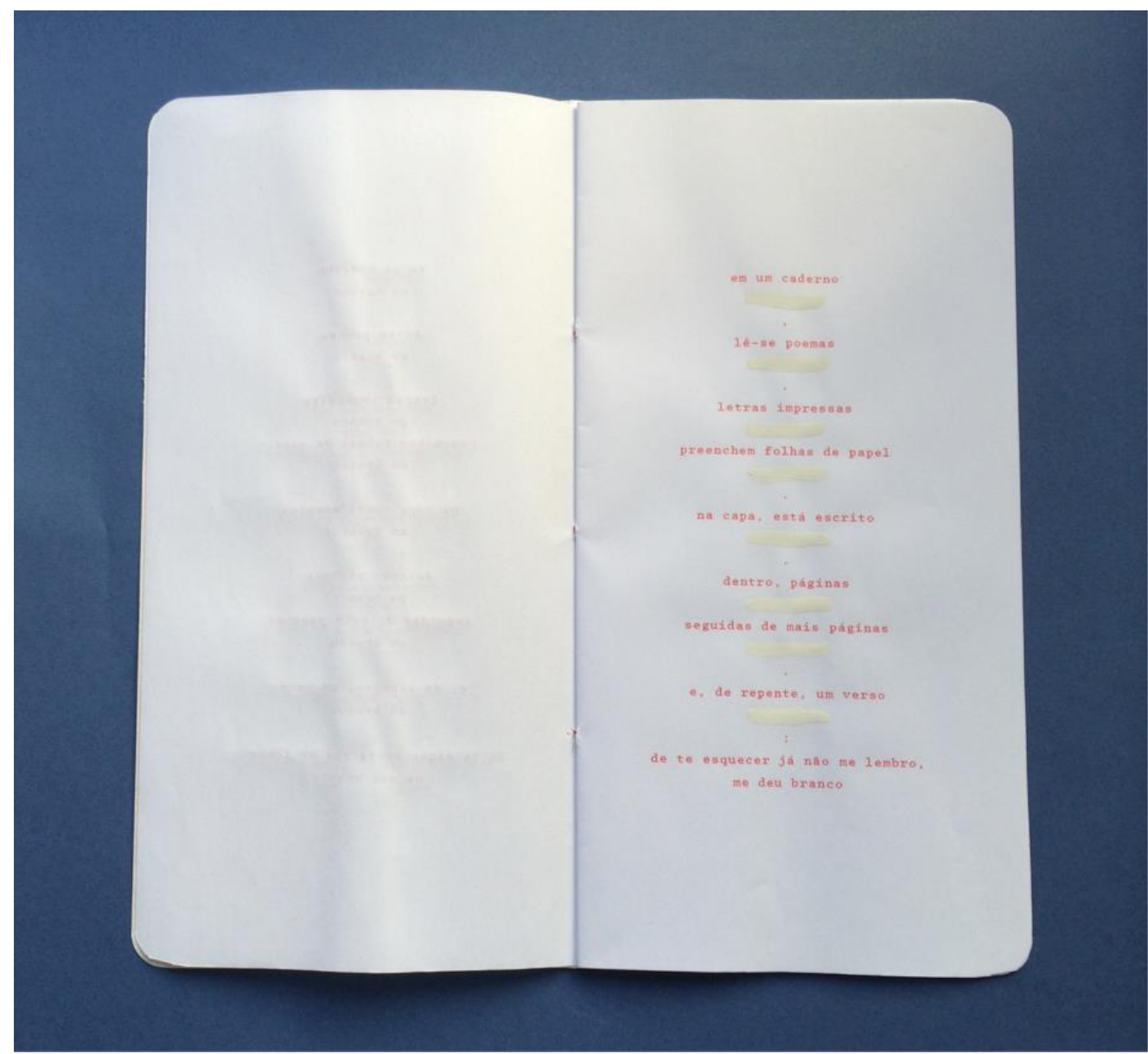

Fonte: Acervo da autora.

\section{Relações no Plano de Expressão}

Embora tenhamos atingido todas as etapas que nos propusemos a percorrer, nosso maior empenho esteve em analisar as relações no plano de expressão. Com base nas relações concebidas por Hjelmslev em Prolegômenos a uma Teoria da Linguagem (2006) observamos nas obras Pequeno compêndio dos fantasmas interiores, Acordo mal e Em branco a existência de dependência entre as linguagens verbal e visual e, por conseguinte, entre seus elementos grafemáticos e plásticos. Como essas dependências preencheram as condições de uma análise, nos referimos a tais relações como funções e às linguagens e seus elementos como funtivos. Nas três obras consideramos os funtivos constantes posto ser, a presença de cada um deles, condição necessária para a presença do outro. Com isso, passamos a 
denominar as funções contraídas como interdependências e os funtivos como interdependentes.

O passo seguinte foi investigar quais poderiam ser as dimensões dessas interdependências. Hjelmslev, ao definir a categoria gramatical do caso como uma relação entre objetos e pertencente a um sistema, por definição sublógica (La categoría de los casos, 1978) permitiu pensarmos as relações entre os elementos e as linguagens acionadas num texto sincrético como relações pertencentes a um sistema e, como tal, se dar em diferentes dimensões.

Ancorados em Hjelmslev (1978) e Carmo Jr. (2009) identificamos e analisamos em Pequeno compêndio dos fantasmas interiores, Acordo mal e Em branco as três dimensões observadas por Hjelmslev no sistema casual:

(a) primeira dimensão - direção - relação marcada pelo par de termos aproximação/afastamento (acercamiento/alejamiento). Nesta dimensão foram consideradas as categorias topológicas (espacialidade) em relação ao todo da obra (temporalidade);

(b) segunda dimensão - intimidade - relação marcada pelo par de termos coerência/incoerência (coherencia/incoherencia). Nesta dimensão analisamos os graus de intimidade entre as categorias cromáticas, eidéticas e matéricas, levando em consideração a interioridade ou o contato entre os elementos;

(c) terceira dimensão - relação marcada pelos termos subjetividadeobjetividade. Nesta dimensão examinamos se a relação entre os elementos considera o ponto de vista do observador, isto é, se as relações entre os elementos são alteradas ou não, conforme a mudança de posição do observador.

Com base nas análises, consideramos que as três dimensões estão sempre presentes nas relações entre os elementos no plano de expressão de um texto verbovisual. Diferente do que ocorre no sistema da língua, no qual, segundo Hjelmslev, as línguas podem apresentar uma, duas ou três dimensões, vislumbramos que as relações entre os funtivos de um texto verbovisual preencham sempre as três 
dimensões do sistema. Naquelas dimensões em que não se observe um dos termos que caracteriza a dimensão, propomos que a relação seja considerada como neutra, porém não inexistente.

\section{Conclusões}

Ao final das análises, consideramos que os objetivos desta pesquisa foram alcançados. Embasados em conceitos fundamentais da semiótica discursiva e de autores como Hjelmslev (1978, 2006), Carmo Jr. (2009) e Teixeira (2004, 2009) evidenciamos a possibilidade de pensar as relações entre componentes no plano de expressão de semióticas sincréticas como dependências e estas, observadas em três dimensões: sob o ponto de vista da direção (espacialidade e temporalidade), da intimidade (formantes cromáticos, matéricos e eidéticos) e da consideração ou não do ponto de vista do observador (objetividade/subjetividade).

Concluímos que a pesquisa pode contribuir tanto para o campo da Educação como para a disciplina que Ihe deu suporte. Para o ensino da arte, seja em contextos escolares ou fora deles, reafirmamos aos atores envolvidos no processo a necessidade da inserção de textos e práticas do cotidiano para a leitura. O zine é um potente material para a experimentação expressiva e conceitual. Além do objeto, a pesquisa também fornece subsídios teóricos e metodológicos para o aprofundamento da leitura de imagens, com base na semiótica discursiva.

No campo da semiótica discursiva, a investigação pretende colaborar com pesquisas que tenham como objeto empírico de estudo manifestações sincréticas verbovisuais. $O$ estudo das relações entre linguagens pensadas como dimensões do sistema dos casos almeja contribuir para uma sistematização da leitura do plano de expressão de textos sincréticos. A semiótica discursiva não dispõe, até o momento, de um percurso gerativo de sentido, de um simulacro para a leitura do plano de expressão como o possui para o plano de conteúdo.

Pensada como algo que não se encerra em si mesmo, a tese aponta para novos questionamentos. Poderíamos, a partir da análise dos zines, concluir que nos textos sincréticos verbovisuais sempre os funtivos são constantes e as relações são de 
interdependência? Ao ponderarmos as relações no plano de expressão, como dimensões, não estaríamos pensando as relações como graus de dependência ou de sincretismo entre as linguagens? Que sentidos podem ser provocados a partir das casas de cada dimensão (positiva, neutra ou negativa), individualmente ou combinadas entre si? Podemos observar as mesmas dimensões em outros textos verbovisuais? Perguntas sobre as quais pretendemos nos debruçar na sequência desta pesquisa.

\section{Referências}

ACASO, María. El lenguaje visual. Barcelona: Paidós, 2009.sẸp?

ANDRAUS, Gazy. As histórias em quadrinhos como informação imagética integrada ao ensino universitário. São Paulo: Programa de Pós-Graduação em Ciências da Comunicação, Escola de Comunicações e Artes, Universidade do Estado de São Paulo, 2006. Tese (Doutorado em Ciências da Comunicação).

BARBOSA, Ana Mae (Org.). Arte-educação: leitura no subsolo. São Paulo: Cortez, 1997.

BARROS, Diana Luz Pessoa de. Teoria semiótica do texto. São Paulo: Ática, 2003.

BARTHES, Roland. Fragmentos de um discurso amoroso. In: BARTHES, Roland. O grão da voz: entrevistas, 1961-1980. São Paulo: Martins Fontes, 2004. P.394-406.

BARTHES, Roland. O terceiro sentido. In: BARTHES, Roland. O óbvio e o obtuso: ensaios críticos III. Rio de Janeiro: Nova Fronteira, 1990. P.45-61.

BARTHES, Roland. A câmara clara: nota sobre a fotografia. Rio de Janeiro: Nova Fronteira, 1984.

CARMO JR, José Roberto do. Estratégias enunciativas na produção do texto publicitário verbovisual. In: OLIVEIRA, Ana Cláudia de; TEIXEIRA, Lucia (Orgs.). Linguagens na comunicação: desenvolvimentos de semiótica sincrética. São Paulo: Estação das Letras e Cores, 2009. P.169-184.

FIORIN, José Luiz. Para uma definição das linguagens sincréticas. In: OLIVEIRA, Ana Cláudia de; TEIXEIRA, Lucia (Orgs.). Linguagens na comunicação: desenvolvimentos de semiótica sincrética. São Paulo: Estação das Letras e Cores, 2009. P.15-40.

GREIMAS, Algirdas Julien. Da imperfeição. São Paulo: Hacker Editores, 2002.

GREIMAS, A. J.; COURTÉS, J. Dicionário de semiótica. São Paulo: Contexto, 2008.

GREIMAS, A. J.; COURTÉS, J. Semiótica: diccionario razonado de la teoría del lenguaje. Tomo II. Madrid: Editorial Gredos, 1991.

HJELMSLEV, Louis. Prolegômenos a uma teoria da linguagem. 2. ed. reimp. São Paulo: Perspectiva, 2006. HJELMSLEV, Louis. La Categoría de los Casos. Madrid: Editorial Gredos, 1978.

JAGODZINSKI, Jan. As negociações da diferença: arte-educação como desfiliação na era pósmoderna. In: GUINSBURG, J; BARBOSA, Ana Mae (Orgs.). O Pós- modernismo. São Paulo: Perspectiva, 2005. P.661-689.

KALKO, Ale. Pequeno compêndio dos fantasmas interiores.

LERM, Ruth Rejane Perleberg. Leitura de textossincréticos verbovisuais: relações entre linguagens em (fan)zinesbrasileiros. Porto Alegre: Programa de Pós-Graduação em Educação, Faculdade de Educação, Universidade Federal do Rio Grande do Sul, Porto Alegre, 2017. Tese (Doutorado em Educação). 
LUPTON, Ellen. A produção de um livro independente Indie Publishing: um guia para autores, artistas e designers. São Paulo: Edições Rosari, 2011.

MAGALHÃES, Henrique. O rebuliço apaixonante dos fanzines. João Pessoa: Marca de Fantasia, 2013. MAGALHÃES, Henrique. O que é fanzine. São Paulo: Editora Brasiliense, 1993.

MAGALHÃES, Henrique Paiva de. Os fanzines de histórias em quadrinhos, o espaço crítico dos quadrinhos brasileiros. São Paulo: Programa de Pós-Graduação em Comunicação, Escola de Comunicações e Artes, Universidade de São Paulo, 1990. Dissertação (Mestrado em Ciências da Comunicação).

MUNIZ, Cellina Rodrigues (Org.). Fanzines: autoria, subjetividade e invenção de si. Fortaleza: Edições UFC, 2010.

MUNIZ, Cellina Rodrigues. A experiência pedagógica de uma escrita dionisíaca. Fortaleza: Programa de Pós- Graduação em Educação Brasileira, Faculdade de Educação, Universidade Federal do Ceará, 2009. Tese (Doutorado em Educação).

NASCIMENTO, Melissa Eloá Silveira. Pedagozinando em sala de aula: artes de dizer e pedagogias de fazer. Rio de Janeiro: Programa de Pós-Graduação em Educação, Faculdade de Educação, Universidade do Estado do Rio de Janeiro, 2010. Dissertação (Mestrado em Educação).

PENTEADO, Hildebrando Cesario. Fanzine: expressão cultural de jovens em uma escola da periferia de São Paulo. São Paulo: Programa de Pós-Graduação em Educação: História, Política e Sociedade, Pontifícia Universidade Católica de São Paulo, 2005. Dissertação (Mestrado em Educação).

PINTO, Renato Donizete. O Fanzine na Educação: algumas experiências em sala de aula. João Pessoa: Marca de Fantasia, 2013.

TEIXEIRA, Lucia. Para uma metodologia de análise de textos verbovisuais. In: OLIVEIRA, Ana Cláudia de; TEIXEIRA, Lucia (Orgs.). Linguagens na comunicação: desenvolvimentos de semiótica sincrética. São Paulo: Estação das Letras e Cores, 2009. P.41-77.

TEIXEIRA, Lucia. Entre dispersão e acúmulo: para uma metodologia de análise de textos sincréticos. Gragoatá, Niterói, n.16, 2004. $\quad$ Disponível $\quad$ em: <http://www.gragoata.uff.br/index.php/gragoata/article/view/586/451>. Acesso em: 23 fev. 2017.

TRIGGS, Teal. Fanzines: the DIY Revolution. San Francisco: Chronicle Books, 2010.

UESUGI, Hannah. Em branco. 2014.

UESUGI, Hannah. Acordo mal. 2013.

WERTHAM, Fredric. The world of fanzines. A special form of communication. London; Amsterdam: Southern Illinois University Press, 1973.

\section{Ruth Rejane Perleberg Lerm}

Doutora e Mestre em Educação pela Universidade Federal do Rio Grande do Sul (UFRGS), especialista em Arte-educação e licenciada em Educação Artística pela Universidade Federal de Pelotas (UFPel). Professora dos cursos técnicos e de bacharelado em Design do Instituto Federal de Educação, Ciência e Tecnologia Sul-rio-grandense (IFSul), Campus Pelotas. Atualmente coordena o Curso Técnico em Comunicação Visual. Integrante do Grupo de Pesquisa em Educação e Arte (GEARTE/CNPq). Sua pesquisa está voltada para o estudo de textos verbovisuais tendo como aporte teórico a semiótica discursiva.

E-mail: ruthlerm@yahoo.com.br

Currículo: http://lattes.cnpq.br/0463753444943987

Recebido em 2 de março 2018 Aceito em 20 de abril de 2018 